\title{
COMO SOMBRAS DE NUBES EN EL FONDO DEL LAGO
}

\section{Miquel Porta}

Resumen: Este texto es una invitación a que personas familiarizadas con las humanidades o las ciencias sociales caten un es tudio excepcional sobre las causas ambientales intrauterinas del cáncer de mama, y valoren sus posibles significados e implicaciones culturales, psicológicas, filosóficas, morales y políticas. Tras madurar más de 50 años, el principal hallazgo del estudio fue que el cáncer de mama era unas tres veces más frecuente en I as mujeres cuyas madres tenían mayores concentraciones corporales del plaguicida DDT cuando estaban embarazadas de aquellas. El estudio plantea cuestiones sobre los tempos personales y sociales; limitaciones y posibilidades de las protecciones individuales y colectivas ante los tóxicos; costes humanos (in)visibles de ciertos modelos de desarrollo; posibilidades de t ratar con delicadeza y eficiencia los efectos de los contaminantes sobre los fetos, así como cuestiones relativas a nuestra conciencia corporal, socioambiental y tecnológica, creencias y vivencias sobre las causas de las enfermedades, políticas públicas y justicia transgeneracional, entre otras.

Palabras clave: cáncer; causalidad; historia económica; plaguicidas; políticas.

\section{Abstract: LIKE SHADOWS OF CLOUDS IN THE DEPTHS OF A LAKE}

This text is an invitation for persons familiar with humanities or social sciences to taste an exceptional study on the intrauterine environmental causes of breast cancer, and to assess the potential cultural, psychological, philosophical, moral, and pol itical meanings and implications of the study. After maturing for over 50 years, the main finding of the study was that breast cancer was about three times more frequent among women whose mothers had higher body concentrations of the pesticide DDT when they were pregnant of such women. The study poses questions on personal and social tempos; limitations and possibilities of individual and collective protection from toxic compounds; the (in)visible human costs of some models of development; difficulties of addressing with finesse and efficiency the effects of contaminants on fetuses, as well as questions on our bodily, socioenvironmental and technological conscience, beliefs and experiences on the causes of illnesses, public policies, and transgenerational justice, among others..

Keywords: cancer; causality; economic history; pesticides; policies.

Artículo recibido: 21 noviembre 2015 ; aceptado: 29 diciembre 2015. 
Cuántas personas quedarán que todavía recuerden, que conserven como una frágil reliquia una imagen precisa, no agregada retrospectivamente, no inducida por el conocimiento de lo que estaba a punto de ocurrir, lo que nadie preveía...(1).

Sin duda la noticia mereció ser publicada en I os mejores medios de comunicación pero, naturalmente, no en todos lo fue. Sí la difundieron algunos como Time, The Washington Post, Chicago Tribune, Forbes, Reuters, Fox News, National Geographic o la misma Science, de gran prestigio ésta en el mundo científico. En España, ninguno.

Mas da igual quién se fijó en la relevancia de la noticia. Y nada importa que haya transcurrido un cierto tiempo desde entonces: cuando un "coñac" ha madurado durante más de cincuenta años, como es el caso, da igual que se pusiese a la venta hace unos meses, el destilado está aquí con su misterio y supuesto esplendor. Podemos abrir la noticia hoy y bebérnosla entera, sorbo a sorbo, con los cinco sentidos. $Y$ con el sexto también, pues bien dice Alighiero Boetti, el artista conceptual turinés, que pensar es el sexto sentido.

Constatemos rápidamente que a muy pocos amantes del vino, el coñac o el whisky se les pasaría por alto una noticia que les ofreciese probar gratis un caldo con más de 50 años de antigüedad. Son productos atractivos, raros y, por supuesto, bastante caros: en las tiendas especializadas una botella puede superar los cien mil y hasta el millón de euros. Al parecer el malta escocés Macallan de 64 años, en botella Lalique, se vende por unos 410.000 euros. El coñac Henri IV Dudognon Heritage se paga a unos 2 millones de dólares; pero es que viene en una botella con oro y diamantes.

Y aunque sólo seamos bebedores ocasionales, si algún medio nos avisa difícilmente rechazaremos la oferta de probar gratis esos destilados excepcionales. Lo cual no quita, al contrario, que uno no vaya a detenerse unos instantes antes a pensar sobre la experiencia que le espera. Durante y tras la cual también intentará percibir y retener aromas, sabores y sensaciones de diversa índole, siquiera por 
unos instantes, en la nariz, la boca, el paladar, la mente; si puede ser, por muchos años, en la mente y el alma. También cabe que todo sea un trago fugaz.

Probemos. Te ofrezco saborear algo excepcional; en v arios sentidos, literalmente más raro, infrecuente e inquietante que esos caros alcoholes. Algo con más de 50 años, sí, literalmente. De un precio aún mayor. $Y$ de un valor sin duda superior. Al menos desde 2008 la recesión nos ha recordado a casi todos la diferencia entre el precio y valor de las cosas (2) ¿verdad? De ello también trata este texto.

Te propongo saborear un estudio científico que ha tardado más de 50 años en llegar a nuestras mesas. Lo sirvieron una revista científica (3), la correspondiente nota de prensa (4), y los medios de comunicación mencionados antes (¿mensajeros o comensales probables de un intelectual español?). En concreto, el estudio se ha estado haciendo -día a día, madurando, aunque no en barricas de roble- 54 años. ¿Decepcionada? Reconozco, naturalmente, que hay una gran diferencia entre saborear un es tudio y un vino. Sé que no es fácil. Pero dejemos eso: quizá la diferencia sea nimia y sólo dure unos instantes, los del trago. Perdurables pueden ser en ambos casos las sensaciones. Espero que así será. Permite que te sirva.

\section{La primera añada de una viña excepcional}

El estudio se concibió a finales de la para muchos lejana década de 1950, cuando algunas lectoras de este artículo no habían nacido, otras eran pequeñas, o sus padres, jóvenes. Ayer mismo. La familia como espacio privilegiado de la memoria: un viñedo fértil en el que ésta se planta y permanece.

El trabajo de c ampo del estudio empezó hacia 1959; desde entonces y durante 54 años -ique se dice pronto!- las autoras del mismo hicieron un seguimiento de más de 20.754 embarazos. Fantástico. Éstos tuvieron lugar entre 1959 y 1967, los años de apogeo del uso del plaguicida DDT en Estados Unidos; ahí se calcula que en 1965 se produjo el pico de contaminación de los alimentos por DDT (5). Quizá con un cierto retraso (los datos de producción de 1940-1955 son 
dudosos, y no parece haberlos sobre la distribución geográfica de su uso), también en España el DDT se fabricó y utilizó ampliamente. Todavía viven muchos que recuerdan al "flit", palabro con el que se designaba al insecticida y su añejo fumigador doméstico. El vocablo parece proceder de "Flix", la localidad tarraconense en cuyo embalse han permanecido sumergidas durante décadas miles de toneladas de residuos tóxicos generados por la fábrica electroquímica, que empezó a fabricar DDT hacia 1946. La compleja e imperfecta remediación de ese desastre ambiental, consentido durante el franquismo y después durante treinta años de democracia, la seguimos pagando hoy los ciudadanos. Los tempos de la historia.

En España el DDT se usaba masivamente ya en 1957, con un período de máximo uso entre 1965 y 1977, aproximadamente. Sí, estamos también ante cuestiones de historia económica y economía política: franquismo, autarquía, agricultura, plaguicidas, Planes de Desarrollo, Transición, efectos positivos y nocivos de esos modelos económico-políticos. Y modelos culturales: conciencia ambiental y tecnológica, consumo, salud pública. Conciencia. Filosofía. ¿Qué reflexiones aportan las Humanidades? Tenemos en las manos además cuestiones delicadas y relevantes para la psicología y la cultura humanas; como nuestra ancestral dificultad para lidiar con efectos sociales e individuales relativamente invisibles, nocivos y a largo plazo, (in)visibles (6). Y más si conciernen a fetos y niños. ¿Cuándo empezó la exposición generalizada de los fetos españoles al DDT? Quizá a partir de 1960 1965. Creo que pocas personas nacidas antes estuvieron expuestas al DDT en el vientre materno.

\subsection{4 embarazos, 9.300 niñas, 118 cánceres de mama... ¿demasiadas cifras para un humanista?}

No creo: los humanistas también gustan del os buenos datos. Ese seguimiento tan prolongado -54 años, desde 1959 hasta 2013- es una auténtica hazaña científica. Le faltará glamour tecnológico o bouquet, pero lo es. Aunque es lógico que de entrada el trago no te sepa a nada (2). 
El artículo que comentamos (5) es obra de Barbara Cohn y sus colegas de los Institutos de Salud Pública de Berkeley y Oakland, en California, el Departamento de Toxicología Ambiental de la Universidad de California en Davis, el Laboratorio de Química Ambiental del Departamento de Control de S ustancias Tóxicas y otras instituciones de California. Bodegas inauditas en una cata, sí. Todo parece lejos de los temas culturales y políticos habituales.

La primera parte del estudio se hizo en unos años (1959 - 1967) en los que a buen seguro nacieron las madres y tías de muchas lectoras de este artículo, o las propias lectoras, hermanas y amigas. En esos 8 años las investigadoras recogieron sangre de las 20.754 mujeres embarazadas, una ingente vendimia. Sí, Borges y otros ya advirtieron de que es temerario acuñar metáforas (7).

Las muestras de sangre se almacenaron en congeladores a $-20^{\circ} \mathrm{C}$. La media de edad de las chicas que donaron las muestras fue de 27 años. Sangre: más que una metáfora. Estas mujeres dieron a luz a 9.300 niñas. El seguimiento consistió básicamente en conocer las principales enfermedades que se diagnosticaban a las niñas a lo largo de la vida. Técnicamente es un estudio prospectivo de casos y controles anidado en una cohorte (8). Pero conocer esos detalles, como los de la elaboración de un whisky, no es necesario para entenderlo y ¿saborearlo?.

Esas niñas nacidas entre 1959 y 1967 hoy tienen entre 56 y 48 años. Han tenido pues un cierto tiempo para desarrollar un cáncer de mama y, en concreto, 118 ya lo han desarrollado; todas antes de los 52 años.

Hace poco, las investigadoras descongelaron una muestra de sangre de las 118 madres cuyas hijas han tenido un cáncer de mama y otra muestra de 350 madres ("controles") cuyas hijas no han $t$ enido la enfermedad. $Y$ acto seguido compararon los niveles de ciertas sustancias en la sangre de unas y otras madres.

Quizá esperabas, no sin razón, que la sangre analizada fuese la de las hijas. ¿Qué sentido tiene comparar los niveles o concentraciones de ciertas sustancias en la sangre de madres cuyas hijas han desarrollado o no un cáncer de mama? La 
principal razón es: numerosos estudios han mostrado que algunas exposiciones laborales y ambientales que los fetos experimentan (exposición a tóxicos, nutrientes saludables, desnutrición, tabaco) contribuyen a causar o a prevenir enfermedades que se manifiestan décadas después del nacimiento, durante la infancia y en la edad adulta; como por ejemplo la diabetes tipo 2, hipertensión y otras enfermedades cardiovasculares, algunos cánceres, enfermedades pulmonares y renales, osteoporosis (7).

Muchos estudios han demostrado que los niveles de D DT y otros compuestos químicos en la sangre de las madres son similares a los niveles en el líquido amniótico, el líquido que rodea al feto, como un lago en el que flota una isla. EI DDT y otros tóxicos atraviesan bien la placenta: pasan desde la sangre de la madre al feto. Imágenes, emociones, sinsabores.

Las tres sustancias que se analizaron en la sangre de las madres fueron el p,p'-DDE, que es el principal compuesto en el que se degrada el plaguicida DDT; el p,p'-DDT, que es la principal sustancia de dicho plaguicida; y el o,p'-DDT, otra sustancia contenida en el producto comercial. Estas sustancias son disruptores endocrinos (perturban el sistema hormonal) y, entre otros efectos, tienen actividad estrogénica (imitan y perturban a los estrógenos, hormonas sexuales, principalmente femeninas, producidas sobre todo por los ovarios); esa actividad estrogénica es especialmente clara en el caso del o,p'-DDT.

\section{Catemos los resultados}

Las concentraciones sanguíneas de las tres sustancias mencionadas fueron más altas en las madres de las chicas con cáncer de mama que en las madres de las chicas controles. Las chicas que estuvieron expuestas a concentraciones más altas de o,p'-DDT cuando estaban en el vientre de sus madres tuvieron un riesgo 3,7 veces mayor de cáncer de mama que aquellas que estuvieron expuestas a las concentraciones más bajas; es decir, su riesgo de cáncer de mama casi cuadriplicaba. Por su parte, el p,p'-DDT multiplicaba el riesgo por 2,9 (casi lo triplicaba). 
Estos resultados no se explicaban por factores como la edad y peso de las madres, su raza o historia de cáncer de mama. A su vez, cuando se tuvieron en cuenta las concentraciones de o,p'-DDT, las chicas cuya madre había tenido alguna vez cáncer de mama tenían un riesgo seis veces mayor de cáncer de mama que aquellas cuya madre no lo había tenido. Este riesgo podría tener componentes genéticas, epigenéticas (9) y ambientales; por ejemplo, con toda seguridad madre e hija estuvieron expuestas a otros contaminantes ambientales. En pocas palabras, el cáncer de mama fue más frecuente en las mujeres cuyas madres tenían mayores concentraciones de DDT cuando estaban embarazadas de ellas.

\section{Limitaciones y horizontes del estudio}

Todo estudio científico sobre salud humana tiene limitaciones, sea un estudio del aboratorio, clínico o epi demiológico. ¿Cuáles eran las principales limitaciones de este estudio? Una, que de momento el seguimiento sólo ha durado 54 años. Cuando el seguimiento sea más prolongado (cuando la mayoría de chicas tenga ya más de 60 años y muchas superen los 70 ), podrán analizarse las posibles causas de los cánceres de mama de aparición más alejada de la menopausia, que suelen tener causas algo distintas de los cánceres anteriores o cercanos a la menopausia.

Asimismo, la cifra de $3 \mathrm{c}$ ompuestos tóxicos analizados es baja: será conveniente que en adelante las investigadoras analicen un $\mathrm{n}$ úmero mayor de exposiciones, como el hexaclorobenceno, análogos del lindano y otros plaguicidas, dioxinas, policlorobifenilos (PCBs), parabenos, alquilfenoles o c ompuestos polibromados. Todos ellos se han asociado en algún estudio anterior con el riesgo de cáncer de mama, y las personas solemos acumular en el interior de nuestro cuerpo complejos "cócteles" de esos compuestos (6). También deberían analizarse exposiciones protectoras.

Además, las investigadoras podrán tener en cuenta factores de riesgo a los que las chicas estuvieron expuestas a partir del nacimiento, como la obesidad en la infancia y adolescencia, la exposición a otros estrógenos, una menarquia (primera 
Como sobras de nubes en el fondo del lago

Miquel Porta

menstruación) temprana o u na menopausia tardía. Como toda enfermedad multicausal, cada cáncer de mama puede tener distintos conjuntos de factores causales (10). Causalidad, una antigua cuestión filosófica, científica, cultural y política.

\section{Ventajas, implicaciones}

¿Qué característica hace excepcional a este estudio? Que es el primero que ha cuantificado la exposición intrauterina a DDT y que la ha podido relacionar con la aparición o no de cáncer de mama en las cinco décadas posteriores al nacimiento. Hasta ahora, diversos estudios sobre el riesgo de este cáncer potencialmente debido al DDT y otros compuestos tóxicos persistentes habían medido a los tóxicos durante la etapa adulta, cuando puede que la mama ya no sea vulnerable a ellos, o cuando una parte de ellos ya ha sido eliminada del cuerpo.

Barbara Cohn manifestó que "este estudio es el primero que aporta pruebas directas de que la contaminación química de las mujeres embarazadas puede tener consecuencias a lo largo de la vida para el riesgo de cáncer de mama de sus hijas y de que las exposiciones más elevadas al DDT in utero hacen que las mujeres tengan un mayor riesgo de cáncer de mama." La Dra. Cohn también dijo que "los hallazgos nos piden que pongamos mayor atención en encontrar y controlar las causas ambientales del cáncer de mama que operan en el vientre materno" (4).

\section{Historia económica del líquido amniótico}

EI DDT se había utilizado ampliamente durante la Segunda Guerra Mundial. En Estados Unidos su uso en la población general empezó en 1945, y alcanzó su mayor intensidad a finales de los años cincuenta. Por ende, las muestras de sangre de las madres de las casos y las controles (recogidas entre 1959 y 1967) tuvieron unas concentraciones de DDT muy superiores a las de décadas posteriores.

Pero hoy es normal -al menos en el sentido de habitual, y en el sentido estadístico, pero no necesariamente en el sentido psicológico, moral y político- que en el líquido amniótico de mujeres embarazadas se detecten numerosos 
compuestos químicos artificiales. Que no son agua bendita. Ni sombras de nubes en el fondo del lago. En Canarias, por ejemplo, en dos de cada tres muestras de líquido amniótico se detectó algún tóxico: el más frecuente fue el hexaclorobenceno (detectado en el 66\% de las chicas), seguido del lindano (28\%). Las concentraciones de estos y otros plaguicidas fueron superiores en las chicas más jóvenes (11). Parémonos a sentir a qué sabe ese trago. ¿Demasiado tánico?

Actualmente, las chicas expuestas al DDT in utero durante la década de 1960 están alcanzando las edades en las que el riesgo de aparición del cáncer de mama es máximo: en España la mayor incidencia de es a enfermedad se da e $n$ mujeres que tienen entre 55 y 60 años (nacidas, por tanto, entre 1960 y 1955). La mediana de edad al diagnóstico es de 58 años.

Estados Unidos prohibió el DDT desde los años 70. Una decisión política basada en conocimientos científicos; otro buen tema. España lo hizo entre 1975 y 1977. Malos años para la lírica: no se sabe cuán estricto fue el cumplimiento de la legislación. Pero desastres como el de Sabiñánigo (12) sugieren que la ciudadanía (casi toda la izquierda política incluida) estaba poco al tanto de estos temas. Tras múltiples gobiernos democráticos desde 1977-1979, hoy los ingentes residuos incontrolados de lindano en Huesca y demás lugares siguen siendo un ejemplo de negligencia e i mpotencia; y de I a economía política de los tóxicos persistentes. Inquinosa, una fábrica de lindano (plaguicida organoclorado como el DDT), situada cerca del río Gállego, cerró intempestivamente en 1989. Pero el producto tóxico arrojado en vertederos penetró en el subsuelo e impregnó las tierras y aguas de miles de personas. Durante 25 años. No es un caso trivial para la filosofía política.

Hoy, en Estados Unidos, en España y en todos los países del mundo que han analizado el problema, el p,p'-DDE se detecta en cerca del 100\% de recién nacidos. Incluso el p,p'-DDT suele detectarse en $\mathrm{m}$ ás del $70 \%$ de la población general. Sí, todavía hoy en dí a -aunque, afortunadamente, a concentraciones inferiores a las que eran comunes en los años sesenta. Además, 75 años después 
del inicio de la Segunda Guerra Mundial, el DDT continúa presente en las cadenas alimentarias animal y humana. Los tempos de las sociedades modernas.

\section{Sensaciones, preguntas, conclusiones}

La cata del añejo whisky, coñac o vino ha terminado. ¿Cuáles han sido las sensaciones? Esperemos que complejas. Acaso los aromas y fragancias no siempre han sido frescos y balsámicos, aunque quizá sí nítidos y potentes; sin las tonalidades rubí, caoba o teja de los viejos crianzas. ¿Qué posgusto te queda?

Sé que la analogía entre la cata de un vino y la de un estudio científico es difícil -y quizá estéril-, pues las experiencias son bien distintas; pero he querido conectarlas con tensores de ac ero y probar qué sensaciones creaba la bóveda resultante.

Quizá el estudio te haya cautivado o inquietado por razones como éstas o parecidas: naciste entre 1950 y 1970 y te han diagnosticado un cáncer de mama; estuviste embarazada de una niña en ese período y -como tantas otras vecespiensas en las enfermedades que deseas que nunca sufra; a veces sientes cierto temor a sufrir dicha enfermedad, o tienes una mujer cercana que la ha padecido; no naciste en ese período y no tienes a nadie cerca que tenga cáncer de mama pero te interesan las causas, ambientales u ot ras, de en fermedades como el cáncer de mama; no entiendes bien por qué sabemos, hablamos o actuamos tan poco sobre las causas del cáncer de mama.

\section{Otras catas}

Pues terminemos la velada catando otros néctares. Como los que destilan los artistas. Ya en los años 50 dijo Rachel Carson (13), autora del clásico sobre los efectos adversos del DDT, Primavera silenciosa: "El propósito de l a ciencia es descubrir e iluminar la verdad. Y ése, entiendo, es el propósito de la literatura. Me parece a mí, entonces, que no puede haber una literatura de la ciencia separada" (14). Lo que hay que hacer está claro: integrar culturas humanísticas y científicas (2, 6-8). Pues hagámoslo. Probemos. 
Así Michael Ondaatje en su poema, La historia (15) (fragmento):

For his first forty days a child is given dreams of previous lives. Journeys, winding paths, a hundred small lessons and then the past is erased.

Some are born screaming, some full of introspective wandering into the past-that bus ride in winter, that sudden arrival within a new city in the dark. And those departures from family bonds leaving what was lost and needed. So the child's face is a lake of fast moving clouds and emotions.
Para sus primeros cuarenta días a una niña se le dan sueños de vidas anteriores. Viajes, senderos sinuosos. cien breves lecciones y luego el pasado es borrado.

Algunas nacen gritando, algunas, llenas de andanzas introspectivas por el pasado -aquel viaje invernal en autobús, la súbita llegada adentro de una nueva ciudad en la oscuridad. Y esas partidas de los vínculos de familia dejando lo que se perdía y era necesario. Así la cara de la niña es un lago de nubes y emociones veloces.

Excepto que not odo el pasado es borrado. Lo s abíamos. La c iencia contemporánea -la epigenética (9), el estudio de Cohn (5)- sólo nos lo señala con otros conocimientos: preñado de afanes, cultura, economía, biología y azar, no siempre el pasado es una nu be pasajera; a veces una par te de él permanece, sobrevolando el lago y nuestro ser, ensombreciéndolo y fluyendo dentro de él, inasible, incorporado (embodied) (7).

O así John Donne, poeta del XVII, quien escribió: "Nadie es una isla, completo en sí mismo (...) y por consiguiente, nunca hagas preguntar por quién doblan las campanas; doblan por ti" (16). Hemingway adaptó el título de su famosa novela de dichos versos (17). Tanto esos dos escritores como el estudio científico que hemos catado nos compelen a preciar esos vínculos embrionarios de $\mathrm{c}$ ada historia personal con todas las demás -algo que muchos seguimos macerando, con aromas siempre renovados de ciruela, especias y madera. Un áspero, lúdico, quizá sensual y rebelde ¿humanismo?.

\section{Miquel Porta Serra}

Investigador del Instituto Hospital del Mar de Investigaciones Médicas (IMIM) Catedrático de Medicina Preventiva y Salud Pública en la Universidad Autónoma de Barcelona.

E-mail: mporta@imim.es. Twitter: @miquelporta. 
FOLIA HUMANÍSTICA, Revista de Salud, ciencias sociales y humanidades № 2, Enero 2016.ISSN 2462-2753

Como sobras de nubes en el fondo del lago

Miquel Porta

\section{Notas}

1. Muñoz Molina A. La noche de los tiempos. Barcelona, Seix Barral, 2009, p. 575.

2. Porta M. Ver lo que nos sale a cuenta. El País, 10 junio 2010, p. 31. http://elpais.com/diario/2010/06/10/opinion/1276120812 850215.html. Porta M. Las quiero a morir. Claves de razón práctica 2013; núm. 226: 172-179. https://goo.gl/SIhPPp

3. Cohn BA y cols. DDT exposure in utero and breast cancer. Journal of Clinical Endocrinology \& Metabolism [publicado por la prestigiosa Endocrine Society] 2015; vol.100, núm. 8, pp. 2865-2872. doi: 10.1210/jc.2015-1841. Publicado en línea el 16 junio 2015. http://goo.gl/ApRBb6

4. Endocrine Society [Nota de prensa] Prenatal DDT exposure tied to nearly four-fold increase in breast cancer risk. 16 junio 2015. https://goo.gl/rknRt6

5. Cohn BA y cols. DDT and breast cancer in young women: new data on the significance of age at exposure. Environmental Health Perspectives 2007, vol. 115, pp. 1406-1414.

6. Porta M. Cuerpos tóxicos. La Vanguardia, 25 noviembre 2009, Suplemento Cultura/s, núm. 388, pp. 1-5. Porta M. Cerco a las sustancias tóxicas persistentes. El País, 30 enero 2007, p. 41. Porta M. Los viajeros ocultos de la obesidad. El País, 18 abril 2006, p. 38. Porta M. Contaminantes para nuestros nietos. El País, 15 enero 2002, p. 26-27. Porta M. Baja la 'contaminación interior'. El País, 13 marzo 2012, p. 36. http://elpais.com/autor/miquel porta/a/

7. Porta M. La secuencia del genoma es una partitura de jazz. Claves de razón práctica 2005, núm. 158, pp. 71-74. http://goo.gl/Ld3nks Porta M. The genome sequence is a jazz score. International Journal of Epidemiology 2003, vol. 32, pp. 29-31.

8. Porta M, ed. A dictionary of epidemiology. $6^{a}$ edición. Nueva York, Oxford University Press, 2014. http://goo.gl/D3V6Y7

9. Son procesos epigenéticos los que regulan o alteran el funcionamiento o expresión de les genes sin modificar la secuencia del ADN; por ej., algunos factores ambientales "encienden" o "apagan" genes importantes para prevenir el cáncer sin causar mutaciones $u$ otras alteraciones en esa secuencia. http://goo.gl/Fkj5qG. Baccarelli A et al. Environmental chemical exposures and hum an epigenetics. International Journal of Epidemiology 2012, vol. 41, pp. 79-105. Stein RA. Epigenetics and environmental exposures. Journal of Epidemiology \& Community Health 2012, vol. 66, pp. 8-13. Jirtle RL, Skinner MK. Environmental epigenomics and disease susceptibility. Nature Reviews Genetics 2007, vol. 8, pp. 253-262.

10. Porta M. ¿Será verdad? Sobre causalidad, confusiones y sesgos. En: Casino G, Fernández E (eds). Epidemiología para periodistas y comunicadores. Barcelona: Fundación Esteve y Asociación Española de Comunicación Científica, 2015, pp. 2331. http://www.esteve.org/cuaderno-epidemiologia/

11. Luzardo OP y cols. Determinants of organochlorine levels detectable in the amniotic fluid of women from Tenerife Island (Canary Islands, Spain). Environmental Research 2009, vol. 109, pp. 607-13. Pueden consultarse importantes resultados de otros estudios sobre concentraciones de t óxicos en sangre de c ordón umbilical en http://www.proyectoinma.org/ 
FOLIA HUMANÍSTICA, Revista de Salud, ciencias sociales y humanidades № 2, Enero 2016.ISSN 2462-2753

Como sobras de nubes en el fondo del lago

Miquel Porta

12. Peiró P. Bajo la amenaza del lindano. El País, 10 noviembre 2014. http://goo.gl/SRORtP

13. Carson R. Discurso de aceptación del National Book Award for Nonfiction de 1952, por su libro The sea around us. En: Lear, L (ed.), Lost woods: The discovered writing of Rachel Carson, Boston, Beacon Press, 1998, pp. 90-92.

14. Carson R. Primavera silenciosa, Barcelona, Crítica, 2013. Una fuente rigurosa de conocimientos sobre medio ambiente y salud de las mujeres, con énfasis en el cáncer de mama, es el Silent Spring Institute: http://www.silentspring.org/

15. Ondaatje M. Handwriting. Nueva York, Alfred A. Knopf, 2000, pp. 60-66. Ondaatje M. Escrito a mano (Handwriting). Madrid, Hiperión, 2000, pp. 114-115. Ondaatje M. The Story. Toronto, House of Anansy Press, 2005.

16. "No man is an island, entire of itself; every man is a piece of the continent, a part of the main. (...) Any man's death diminishes me, because I am involved in mankind, and therefore never send to know for whom the bells tolls; it tolls for thee." En: Devotions Upon Emergent Occasions, Meditation XVII: Nunc Lento Sonitu Dicunt, Morieris. Donne dice que todos estamos socialmente y espiritualmente interconectados. http://goo.gl/OAdF3G

17. San Vicente R. Claroscuros del siglo XX. Iliá Ehrenburg, el hombre que lo vio todo [comentario sobre Gentes, años, vida (Memorias 1891-1967), de lliá Ehrenburg]. Babelia, 10 mayo 2014, pp. 4-6. http://goo.gl/mX8Yu8

Agradecimientos. El autor agradece los valiosos comentarios a versiones anteriores del texto de Anna Mackay, Mònica Mackay, Pía Paraja, Michele Catanzaro, Ricard Meneu y Jordi Gracia. El trabajo del grupo de investigación del autor es en parte posible gracias a las aportaciones del Parc de Salut Mar al Instituto Hospital del Mar de Investigaciones Médicas (IMIM); Gobierno de la Generalitat de C atalunya (2014 SGR 1012); Instituto de S alud Carlos III - FEDER (FIS PI13/00020 y CIBER de Epidemiología y Salud Pública - CIBERESP), Gobierno de España; y Fundació La Marató de TV3 (20132910). Puede apoyar nuestra investigación en http://tinyurl.com/oaddurg

\section{Cómo citar este artículo:}

Porta, M., "Como sombras de nubes en el fondo del lago", en Folia Humanística, 2016; 2: 66-78. Doi: http://dox.doi.org/10.30860/0011.

() 2016 Todos los derechos reservados a la Revista Folia Humanística de la Fundación Letamendi Forns. This is an open access article. 